\title{
冰川渗浸带吸热模型及动坐标求解
}

\author{
蔡 保 林 \\ (中国科学院兰州冰川㑈土研究所) \\ 王她 \\ (邮电部西安第十研究所)
}

关狸词渗带、再冻结、温度

\section{一、引 官}

在冰川学研究中, 根据冰川活动层的水热状态, 将冰川自上而下划为干雪带、渗浸带、附加 冰带和消融带, 其中, 渗浸带是冰川同环境进行能量与物质交换强烈, 内部水热输送最剧烈的 一个带. 此外, 在渗浸带内部的水热输运过程中伴随着一系列渗浸冻结、渗漫成冰、雪层变质 等成冰运动。对于该带向大气的吸热以及自身内部温度变化过程的了解, 有助于全面地认识 冰川的热状态产生与发展的动态过程, 因此, 十分需要建立数学物理模型来深入研究这一问 题,揭示其本质与过程.

在冰川上,当气温升高到一定程度，冰川表面吸收的热量大于放出时,冰川表面就要产生 融化, 出现融水。在附加冰带表面产生的融水, 一部分从表面流走,一部分形成附加冰. 在消 融带表面融水几乎全部从表面流失, 而在渗浸带, 由于表面是可透水的雪层, 因此, 融水就在重 力及毛管力的作用下, 由表面向内部渗透, 但是由于未被融水渗浸过的雪层, 其温度是处于零 度以下. 因此, 融水在向深的一层渗透时, 首先发生冻结, 而融水冻结释放出的相变潜热, 将周 围的雪加热, 直到周围的雪温增加到 $0^{\circ} \mathrm{C}$, 融水才能继续向下渗透. 这样, 在融水的渗透前沿 处,融水发生着相变。值得指出, 在冰川的其它带, 冰川向大气的吸热主要是以传导的方式,热 量由表面靠分子传热向内部输入,但在渗浸带,热量以潜热的形式由融水渗透的方式向内部输 送, 在渗透前沿释放, 增加雪层的温度. 因此, 参透前沿对于下面处于负温的雪层来说, 是一个 恒为 $0^{\circ} \mathrm{C}$ 的热源，并随着时间向下移动 ${ }^{[1]}$.

\section{二、模型及其解}

在上面分析的基础上,我们来考虑冰川渗浸带的吸热模型,取坐标原点于冰川表面, 纵坐 标轴为 $\boldsymbol{y}$, 向下为正, 这样数学模型可表示为

$$
\begin{aligned}
& \frac{\partial T}{\partial t}=a_{i} \frac{\partial^{2} T}{\partial y^{2}}, h(t)<y<\infty, \\
& T(h, t)=0,
\end{aligned}
$$

本文 1988 年 10 月 25 日收到. 


$$
T(y, 0)-f(y),
$$

式中 $T(y, t)$ 为深度 $y$ 处, 时刻 $t$ 时的雪体温度, $h(t)$ 是融水相变处的坐标; 在该处, 由于融 水的冻结释热作用,雪体的温度恒为 $0^{\circ} \mathrm{C}$, 并且随着融水的下渗而向下移动, 假定移动速度为 $\nu, f(y)$ 是渗漫带雪层的初始温度分布， $a$ 是雪层的导温系数. 定解问题. (1)-(3) 的下边 界是移动的, 直接求解较困难, 故作一个变换 $x=y-v \cdot t$, 即在动坐标系中考虑问题, 动系 的纵坐标轴为 $x$, 原点在 $y=h(t)$ 处, 即在融水的相变深度处, 这样方程 (1)一(3) 可以写成 如下形式:

$$
\begin{aligned}
& \frac{\partial T}{\partial t}-v \frac{\partial T}{\partial x}=a, \frac{\partial^{2} T}{\partial x^{2}} ; 0<x<\infty, \\
& T(0, t)=0, \\
& T(x, 0)=f(x) .
\end{aligned}
$$

从热源处, 即从动坐标系的观点看, $\frac{\partial T}{\partial t}$ 的值近似为零 ${ }^{[2]}$, 于是方程 (4)-(6) 变成一个 准稳定的定解问题, 即

$$
\begin{aligned}
& \text { as } \frac{d^{2} T}{d x^{2}}+\nu \frac{d T}{d x}=0, \\
& T(0, t)=0, \\
& T(x, 0)=f(x) .
\end{aligned}
$$

令 $\frac{d T}{d x}=u$, 则方程 (7) 为 $\frac{d u}{d x}+\frac{v}{a_{s}} u=0$, 因此很容易求出定解问题 (7)-(9)的解为

$$
T(y, t)=f(y) \cdot \exp \left(-\frac{\nu}{a_{s}} \cdot t\right) .
$$

由于模型考虑的是雪层的吸热过程, 所以式 (10) 中的时间 $t$ 的适用范围局限在冰川的消

\begin{tabular}{|c|c|c|c|c|c|c|}
\hline 日 期 & 深度（m) & 3 & 5 & 7 & 8 & 11 \\
\hline 6 月中旬 & $\begin{array}{l}\left.\text { 实测( }{ }^{\circ} \mathrm{C}\right) \\
\text { 计算 }\left({ }^{\circ} \mathrm{C}\right)\end{array}$ & $\begin{array}{l}-1.9 \\
-2.7\end{array}$ & $\begin{array}{l}-4.2 \\
-4.8\end{array}$ & $\begin{array}{l}-4.0 \\
-4.9\end{array}$ & $\begin{array}{l}-3.9 \\
-3.9\end{array}$ & $\begin{array}{l}-2.5 \\
-2.0\end{array}$ \\
\hline 7 月中旬 & $\begin{array}{l}\text { 实测 }\left({ }^{\circ} \mathrm{C}\right) \\
\text { 计算 }\left({ }^{\circ} \mathrm{C}\right)\end{array}$ & -0.2 & $\begin{array}{l}-2.8 \\
-2.8\end{array}$ & $\begin{array}{l}-3.1 \\
-4.7\end{array}$ & $\begin{array}{l}-3.4 \\
-3.9\end{array}$ & $\begin{array}{l}-2.8 \\
-2.0\end{array}$ \\
\hline 8 月中旬 & $\begin{array}{l}\text { 实测 }\left({ }^{\circ} \mathrm{C}\right) \\
\text { 计算 }\left({ }^{\circ} \mathrm{C}\right)\end{array}$ & $\begin{array}{l}0 \\
0\end{array}$ & -0.6 & $\begin{array}{l}-1.8 \\
-2.0\end{array}$ & $\begin{array}{l}-1.9 \\
-2.8\end{array}$ & $\begin{array}{l}-1.5 \\
-2.0\end{array}$ \\
\hline
\end{tabular}
融期内.

\section{三、模型的验证}

为了对上述模型进行验证,我们用乌鲁木齐河河源 1 号冰川西支渗浸带 $\mathrm{H}$. 处 1983 年的 实测资料 ${ }^{[3]}$ 进行计算. 1983 年 6-8 月, $10 \mathrm{~m}$ 内雪层的平均密度是 $0.6 \mathrm{mg} \cdot \mathrm{m}^{-}$. 这样雪层的 导温系数可定为 $a_{s}=0.6 \times 10^{-6} \mathrm{~m}^{2} \cdot \mathrm{s}^{-1(4)}$, 雪层的温度是用无线电遥测仪,石英晶体温度探头 测量的, 精度为 $\pm 0.05{ }^{\circ} \mathrm{C}$, 融水渗透前沿的移动速度在整个消融期内是变化的, 但缺乏消融期

表 11983 年消融期雪温的实测值与计算值 
中的完整的、连续的观测资料, 以及本身问题的复杂, 取定值 $0.85 \times 10^{-6} \mathrm{~m} \cdot \mathrm{s}^{-2}$ 作为参透前 沿的移动速度 $v .1983$ 年 5 月中旬, 雪层的温度分布为 $f(y)-A+B y+C y^{2}$, 式中 $A, B$, $C$ 分别为 $-0.81{ }^{\circ} \mathrm{C},-1.42^{\circ} \mathrm{C} \cdot \mathrm{m}^{-3}, 0.119{ }^{\circ} \mathrm{C} \cdot \mathrm{m}^{-2}$. 将 $a_{i}, \nu, f(y)$ 代人 (10) 式, 即可得 到模型的计算值. 实测值与计算值的比较列于表 1 .

由表 1 可知,计算值比较接近于实测值,并且变化趋势与规律基本一致，因此渗浸带的这. 一数学模型能够真实地描述渗浸带在吸热过程中雪层的温度变化, 并由 (10)式可知, 其温度的 变化取决于雪层的导温系数、雪层的初始温度分布以及融水的渗透速度.

\section{参文堿}

[1] Cai Baolin, Xie Zhichu and Huang Maohuan, Cold Regions Science and Technology, 12 (1986), 3949.

[ 2] E. R. G. 埃克特, R. M. 德雷克,传热与传质分析,科学出版社，1983，231一237.

[ 3 ] 王良玮, 遥测数据表说明, 天山水川站年报 (2)，1984，50-120.

[4] Sanderson, T.J., Journal of Glaciology, 20(1978), 83: 263. 